\title{
Industry 4.0: Technology Mapping and the importance of Cognitive Ergonomics
}

\author{
Mateus Faraj Marques Rocha ${ }^{1}$, Karina Fernandes de Oliveira ${ }^{1}$, Igor Polezi \\ Munhoz ${ }^{2}$, Alessandra Cristina Santos Akkari ${ }^{*}$
}

${ }^{1}$ Technology and Science Center, Mackenzie Presbyterian University, Brazil

${ }^{1}$ Federal Institute of Education, Science and Technology São Paulo, Brazil

E-mail: alessandra.akkari@ mackenzie.br

\begin{abstract}
The fourth industrial revolution brings a new paradigm, based on advanced manufacturing and industrial internet. So much has been debated about the knowledge and skills of Operator 4.0. However, the cognitive aspects that are intrinsic to this new paradigm are not considered in these analyses. This work aimed to study the Industry 4.0 under a macro, based on information standardization and technology mapping, and a micro vision focused on cognitive ergonomics. Industry 4.0 attributes pointed to an increasing industry complexity during a technological virtualization process, requiring faster and assertive decisions in the face of a wide range of information. It was found that the Operator 4.0 will oversee the solution of increasingly interdisciplinary problems in a digital environment, requiring denser cognitive efforts and more accurate social-emotional skills, such as communication, motivation, autonomy, perseverance, resilience, collaboration and creativity. The case study pointed out as a highlight the Online Predictive Maintenance, which aims to obtain predictability of failure for each component monitored in machines and equipment. The operating routine linked to this new technology confirms how much mental processes will be required in the face of the Industry 4.0 scenario, since a highflow of information was verified, associated with the rapid decision-making in the use ofnew technologies.
\end{abstract}

Keywords- Industry 4.0, Technology Mapping, Cognitive Ergonomics.

\section{INTRODUCTION}

The Internet of Things (IoT), in which people, processes and products are part of the same system, led to the emergence of Industry 4.0, in which, similarly, supply, manufacturing, delivery and customer are connected in real time. The term Industry 4.0 emerged from the report of the Industry-Science Research Alliance group, which was presented to the German Chancellor and launched at the Hannover Messe in 2013. According to the literature, although there are new solutions arising from the fields of IoT and Industry 4.0, a clear definition of the multiple aspects and perspectives from advanced manufacturing and cyber-physical systems is still not observed, especially in the academic scope [1]. Therefore, systematic reviews of the literature, as well as exploratory and descriptive studies, are important tools to provide evidence for the practices decision making in Industry 4.0 and to allow a more in-depth investigation on the subject by the scientific community.

The implantation worldwide trend of Industry 4.0 follows in advanced industrialized countries and is defining a new era of production based on cyber-physical systems, which in turn are the bases for intelligent machines, industry facilities, and storage systems that to be able to exchange information and make decisions independently from controllers [2]. Thus, this "intelligence" is expected to become responsible for revolutionizing industrial production and associated services. In the scope of Industry 4.0, the automation of manufacturing plants occurs based on technologies such as IoT; Big data; Intelligent Robotics; Industrial Automation; Analytics; and others, considering a connection between technologies and between these technologies and data of labor, inputs, energy and production. Thus, conventional computing will have difficulty staggering with the large data flow and with the complexity of the analysis, and it must become cognitive to process, analyze and optimize the information [3].

From of Industry 4.0, due to its unique and innovative characteristics, may require a new type of worker requiring an optimized formation of qualified professionals to work in this type of organization, in order to guarantee the health, safety and satisfaction in the work environment, as recommended by Ergonomics.

In this sense, on the part of Operator 4.0, mental and cognitive requirements will also be much greater, including the mastery and operationalization of the various technologies, as well as analysis of a variety of workflow, process and environment information to boost quality, operations and accelerate decision making in an 
assertive manner. Therefore, the technological process study of Industry 4.0 under the focus of Cognitive Ergonomics, which is a field of Ergonomics specialization, becomes of great value, since challenges will arise from the new intellectual demands linked to intelligent systems.

Lastly, it is noteworthy that there are still few studies in the literature that propose to investigate the Industry 4.0 under a procedural logic; nor is there research that aims to analyze this new concept under the ergonomics approach in its cognitive domain, being something of great value since challenges will arise from the new mental demands linked to intelligent systems. Thus, the present study had as general objective to study the Industry 4.0 under a macro vision, based on the standardization of information, and under a micro vision, based on ergonomics, particularly in the field of cognitive ergonomics.

\subsection{Industry 4.0: elements and attributes}

In the second half of the 18th century, there was the 1st Industrial Revolution, which mobilized the mechanization of production through the use of water and steam energy, followed by the 2nd Industrial Revolution in the late nineteenth century, in which mass production, with the help of electric power, was the main means of modifying industrial processes. In the middle of the 20th century, the 3rd Industrial Revolution brought the advancement of electronics and manufacturing robotics, and today is already considered the new era of the $21 \mathrm{st}$ century, the 4th Industrial Revolution, in which the digital revolution and the use of Information Technology (IT) will further automate manufacturing, moving into the scope of Advanced Manufacturing and Industrial Internet [2].

According to [3], the integration of the Internet of Things (IoT) and Internet Services (IoS) in the manufacturing process initiated the 4th industrial revolution. IoT enables systems and objects, such as sensors, actuators and mobile phones, to interact and cooperate with their neighbors through "smart" components, to achieve common goals. In this sense, IoT can be defined as a network where cyber-physical systems cooperate with each other through exclusives addressing schemes. The Internet Services (IoS), in turn, allows companies to offer their services through the Internet, consisting of individuals, services infrastructure, business models and the services themselves [4].

Inserted in the fourth industrial revolution, the concept of Industry 4.0, created by German researchers, emerges. In October 2012, a working group in Industry 4.0, chaired by Siegfried Dais, vice chairman of the Board of Directors of Robert Bosch Healthcare, and Henning Kagermann, a member of the German Academy of
Science and Engineering, presented to the Germany federal government, the concept for the integration of advanced control systems with the internet, allowing the communication between people, products and complex systems [5].

The main approach, present in this new industry concept, is based in to become direct the cooperation and communication between people, machines, equipment, products and logistics systems, using production systems with embedded technology, composed of sensors already integrated to intelligent actuators, also counting on the direct communication with the control of operation, called cyber-physical system [6,3].

In fact, an important component of Industry 4.0 is the merging of physics with the virtual world [3], and this integration is possible through the Cyber-Physical System (CPS). According to [7], CPS refers to the integration of computers and physical systems into a single process, in which they both feedback and interact, playing a key role in Industry 4.0, which depend on cyber-physical connections to play its role. The development of CPS is characterized by three phases: (1) the first generation of CPS included identification technologies such as RFID tags, which allowed unique identification, and storage and analysis should be provided as a centralized service; (2) the second generation of CPS is equipped with sensors and actuators with a limited range of functions; (3) third generation CPS can store and analyze data, being equipped with various sensors and actuators and are compatible with the network [6].

Therefore, industry 4.0 can be understood as an intelligent factory that encompasses automation technology and real-time data exchange, using internet, cloud computing and cyber-physical systems to execute, predict and correct process in the fastest and most efficient way [2]

In order to characterize this emerging industry concept, it is worth reflecting on the key attributes of Industry 4.0. Interoperability is a very important element of this new type of industry, because CPS and humans are linked to IoT and IoS, so standards will be a key success factor for communication between CPS from various manufacturers. Thus, interoperability means that all CPS within the plant are able to communicate with each other over open networks. Virtualization, as another attribute, expresses that the CPS are able to monitor physical processes, so that these sensors and data are linked to virtual plant models and simulation models [8].

Decentralization, on the other hand, starts from the point that the growing demand for individual products makes central processes control increasingly difficult. The incorporated computers allow CPS to make their own decisions, and only in cases of failure will the tasks be 
delegated to a higher level. However, to ensure quality and traceability it is necessary to monitor the entire system at any time.

Real-time capability is also critical for Industry 4.0, because for organizational tasks, the data needs to be collected and analyzed in real-time, in this sense, traceability of the process can be verified, and immediate action taken immediately.

Another attribute, the service orientation, states that CPS and other resources are available through IoS and can be used by other participants, being offered both internally and across company boundaries. Finally, there is the modularity attribute, in which modular systems are able to flexibly adapt to changes and expansions by individual modules. Therefore, modular systems may be suitable in case of seasonal fluctuations or changing in product characteristics. $[6,1,9,5]$. Table 1 presents the main attributes in summarized form.

Table. 1: Key attributes of Industry 4.0

\begin{tabular}{|c|c|}
\hline Attributes & Characteristics \\
\hline Interoperability & $\begin{array}{c}\text { Communication and connectivity of cyber- } \\
\text { physical systems, intelligent and human } \\
\text { factories. }\end{array}$ \\
\hline Virtualization & $\begin{array}{c}\text { Virtual copy of Intelligent Factories (data, } \\
\text { simulations, models). }\end{array}$ \\
\hline Decentralization & Decisions without human intervention. \\
\hline $\begin{array}{c}\text { Real Time } \\
\text { Capacity }\end{array}$ & $\begin{array}{c}\text { Data collection, analysis and response in a short } \\
\text { time. }\end{array}$ \\
\hline $\begin{array}{c}\text { Service } \\
\text { Orientation }\end{array}$ & Providing services through Cloud Computing. \\
\hline
\end{tabular}

Source: adapted from [9].

\subsection{Ergonomics and its domain of cognitive specialization}

According to the International Ergonomics Association [10], Ergonomics is the scientific discipline that deals with the understanding of the interactions between humans and other elements of a system, and the profession that applies theories, principles, datas and methods to projects, in order to optimize human wellbeing and overall system performance. The Ergonomics Society (England) defines Ergonomics as the study of the relationship between man and his work, equipment, environment and, particularly, the application of the knowledge of anatomy, physiology and psychology in the solution of the problems that arise from this relationship.

Historically, in 1857, Jastrezebowisky published an article entitled " Ergonomics Essays or Work Science" and the theme was taken up almost a hundred years later, when in 1949 a group of scientists and researchers met in order to formalize the existence of this new field of application interdisciplinary approach to science in 1950, during the second meeting of this group, the neologism "Ergonomics", formed by the Greek terms Ergon (work) and Nomos (rules) was proposed. Thus, in the early 1950s, in England, the Ergonomics Research Society was founded. In 1959, representing a great advance in the area, was founded the International Ergonomics Association - IEA and, in the Brazilian context, in 1983 was created the Brazilian Association of Ergonomics ABERGO [11].

Ergonomics is a science oriented to a systemic approach and that currently extends to all aspects of human activity and whose objective is to study the factors that can influence the productive system, seeking to reduce its consequences for the worker. The fields of ergonomics specialization are physical ergonomics, organizational ergonomics and cognitive ergonomics [12, 13].

Physical ergonomics seeks to study the relationship between physical aspects and work, encompassing the analysis of human anatomy, anthropometry, physiology, and biomechanics, and others. Under this domain, we can mention some topics of study: posture analysis; lifting of cargo; repetitive movements and job design [12, 13].

In the scope of organizational ergonomics, there is the optimization of socio-technical systems, which involve human beings and management techniques, organizational structures, policies and processes. Topics of study in this domain are the work designs, cooperative work, organizational culture and quality management [12, 13].

Finally, cognitive ergonomics, object of study of the present work under the focus of industry 4.0, studies how human beings interact with several elements of a system, analyzing aspects of mental processes, such as perception, memory, motor response, reasoning, and others. Thus, the mental load of work; decision-making; human-computer interaction and stress are topics of cognitive ergonomics $[12,13]$. It is noticed that many of the mentioned items are directly related to the new demands of the Industry 4.0 , due to the flow and speed of transmission of the information, need for accelerated decision making, approaches based on intelligent information, causing in the professional high demands of the processes mental, in order to enter the scope of Cognitive Ergonomics study.

\section{METHOD}

The present work can be considered an exploratory study, integrating bibliographic research and data collection and analysis. Initially, a review of the literature was carried out to identify the guiding principles and concepts of Industry 4.0 in order to be able to develop a technological mapping and analyze the potential implementation challenges. The following academic databases were used: Web of Knowledge, Scopus, SAGE Journals and Scielo; the main fields of research 
encompassed Engineering, Advanced Manufacturing, Industrial Internet, Production Technology, CyberPhysics, Information Security and Cloud Computing. Criteria for inclusion and exclusion of articles, definition of information to be extracted from articles, analysis, discussion and presentation of results were considered as stages of bibliographic review.

For the development of technological process mapping, a single case study was developed using as a model a multinational company from the interior of the state of São Paulo that offers products and services to the market and automotive assemblers, in the same way for power tools and security solutions, and that already applies the precepts of the Industry 4.0 in its line of production. The case study was chosen in order to allow an in-depth analysis and with varied sources of information of a context, that one wishes to study [14]. The choice of the use of a single case, single case study is appropriate when it is desired to determine if what is proposed on a theory is correct, but there are not many similar situations for other comparatives, or if the information is difficult to [15].

One of the organization's processes was taken as an example for study. Said process is based on the maintenance and monitoring of the indicators of the production line of systems for gasoline engines, in order to cover processes essential to the operation of the line through the integrated systems by the concepts of Industry 4.0.

The analysis from the point of view of cognitive ergonomics was based on the identification of the mental requirements to work in the middle of intelligent systems, understanding the necessary qualifications for Engineer 4.0. In addition, the attributes of Industry 4.0 and its potential relationship with cognitive ergonomics were identified.

\section{RESULTS AND DISCUSSION}

Using as a study model the gasoline systems plant of the company on which a case study was carried out, it was observed that industry 4.0 , in relation to industrial development, covers the four aspects that share what one has today, but with the focus and perspective of the future of manufacturing, as below.

(1) Factory: As one of the main components of Industry 4.0, the future factory will involve a new integration, which not only all manufacturing resources (sensors, actuators, machines, robots, conveyors, etc.) will be connected and will automatically exchange information, but will also be conscious and intelligent enough to predict and maintain the machines, to control the production as well as process and manage the manufacturing system. In addition, many manufacturing processes, such as product design, production planning, production and services, will be modularly simulated, and then, connected, so that, in addition to being decentralized, these processes are controlled independently [16].

(2) Business: Kagermann et al. [17] state that Industry 4.0 implies a complete communication between several companies, factories, suppliers, logistics, resources, customers, etc. Each section optimizes its configuration in real time, depending on the demands and status of the associated sections in the network, which makes maximum profit for all cooperatives with limited sharing capabilities. Thus, the future commercial network is influenced by each cooperating section, which could achieve a status of self-organization and convey the real time responses.

(3) Products: Abramovici [18] presents products that will be integrated with sensors, identifiable components and processors that carry information and knowledge to transmit functionality, guiding customers and transmitting feedback to the manufacturing system, and thus, contributing to development of the entire production chain.

(4) Customers: A new purchase method will be provided to customers, which can change your order and ideas at any time during production, even at the last minute at no cost. On the other hand, the benefit of intelligent products allows the customer not only to know the production information of the product, but also to receive usage information depending on their own behaviors [19]

The Line integration and interoperability are, therefore, only part of the Industry 4.0 system, which must be integrated end-to-end, from the customer to the supplier, to optimize the chain as a whole. The significant improvement of the production and information flow was observed in the implementation of the Industry Systems 4.0 in the company being studied.

To guide the development of the industry 4.0, it was observed, in the present work, the adequacy of the proposal recommended by Lee et al. [7] by means of the $5 \mathrm{C}$ architecture (Table 2). This architecture is divided into five levels: connection level; conversion level; cybernetic level; level of cognition; and configuration level.

The connection level focuses on hardware development, which is performed by the sensor network and wireless communication, and the other four levels pay attention to system control and software implementation. At the conversion level, raw data is transformed into useful information using data analysis technologies. The Cyber Level controls the entire network through the CPS. The level of cognition and configuration level involve the 
artificial intelligence in the network, which are considered as future attributes of the fabrication. Manufacturing intelligence is the main target of many researchers interested in Industry 4.0, which is represented by these two levels. Comparing the attributes of these two levels and those of Industry 4.0, the level of cognition is considered as a lower level of Industry 4.0, while the level of configuration tends to reveal higher level characteristics of Industry 4.0 that are considered the industry achievement.

Table. 2: 5 C Architecture for Sector 4.0 Implementation

\begin{tabular}{|c|c|c|}
\hline $\begin{array}{c}\text { Architecture } \\
\text { 5C }\end{array}$ & $\begin{array}{c}\text { Primary } \\
\text { attribute }\end{array}$ & $\begin{array}{c}\text { Main } \\
\text { registration }\end{array}$ \\
\hline $\begin{array}{c}\text { Connection } \\
\text { Level }\end{array}$ & Communicable & $\begin{array}{c}\text { Hardware } \\
\text { Connection }\end{array}$ \\
\hline $\begin{array}{c}\text { Conversion } \\
\text { Level }\end{array}$ & Informational & $\begin{array}{c}\text { Discovery of } \\
\text { information }\end{array}$ \\
\hline $\begin{array}{c}\text { Cybernetic } \\
\text { Level }\end{array}$ & Controllable & $\begin{array}{c}\text { Automated } \\
\text { System }\end{array}$ \\
\hline $\begin{array}{c}\text { Level of } \\
\text { Cognition }\end{array}$ & Self-cognition & $\begin{array}{c}\text { Predictive } \\
\text { Maintenance }\end{array}$ \\
\hline $\begin{array}{c}\text { Configuration } \\
\text { level }\end{array}$ & $\begin{array}{c}\text { Auto- } \\
\text { configuration }\end{array}$ & $\begin{array}{c}\text { Intelligent } \\
\text { production }\end{array}$ \\
\hline
\end{tabular}

Source: adapted from [9].

Therefore, when these various types of ideas (future visions, research examples, and deployment architecture) are merged and summarized under Industry 4.0, several future manufacturing concepts have been abstracted. These concepts are the main design principles of Industry 4.0, which boils down to interoperability and awareness. These two main design principles include many subsets, so that interoperability consists of digitalization, communication, standardization, flexibility, real-time accountability and customization. In turn, predictive maintenance, decision-making, intelligent presentation, self-approval, self-optimization, and self-configuration comprise consciousness.

Analyzing the current manufacturing system and comparing them with Industry 4.0 concepts, it has been found that only manufacturing systems automated recently (automated one station cell, automated as sembly system, flexible manufacturing system, computer and reconfigurable manufacturing system) are involved in the scope of the fourth industrial revolution [20]. Each system is detailed below.

In the case study developed, the company under study adopts the manufacturing system with cells single-station automated, automated assembly, adopting the computer control and integration of the manufacturing, necessary for Industry 4.0, and has flexible cells, adapting the demand variations when required.
- Automated single station cells: In contrast to the manned cell, the automated cell is fully automated. The machines used are not serviced by any worker for more than one machine cycle. Labor costs declined, and productivity increased in comparis on to the manned cell. However, this system also targets batches of constant products. A typical single station automatic cell is composed of one or more automated machines (a set of machines) and an automatic loading and unloading system, such as robots, conveyors, etc. The CNC machine center system is a common example of this system, which can change the tool, position the product and change the axis automatically [21].

- Automated assembly system: the production of bigger manufacturing was built into the assembly automation. Compared to the manual assembly system, this system uses a handling system (usually industrial robots) to replace the workers' tasks. A fully automated assembly system is fixed, which is designed to carry out a fixed order of assembly programming on a specific product. This requires the system to be highly stable without changing the design of the product during production, which means that the system components are limited. However, this system commits itself to products of high demand, usually considered in millions. The system components are similar to those of the manual system, but with two important parts that replace the workers: the handling system and the feeding system. In addition, the control includes sequence control, safety monitoring and quality control, which is also automated. One of the most common applications of automated assembly systems is the machining of lamination and sheet manufacture, lamination operations, spot welding, plating operation and others [21].

- Flexible manufacturing system: it is a highly automated application of "group technology", in which flexibility is the main feature. However, a flexible manufacturing system is designed for a family of specific parts, which is not completely flexible. In this system, multiple workstations are connected to an automated transport power system controlled by a distributed computer system. Every work piece is identified during the production cycle, which is able to change processing immediately. Therefore, in this system, the machine and the use of materials are increasingly improving with a small number of employees and system space, which also reduces 
inventory requirements. In addition, with the high flexibility, the system can make the rapid responsiveness required for change [21].

- Computer-integrated manufacturing system: it was first claimed in 1973 by Joseph Harrington. However, it did not attract the attention of engineers until 1984, when the computer and the automated system began to be developed in the manufacture. The computer integrated into the manufacturing system leads to a fully automated manufacturing, where computers control all functions. In addition, in the simplest system, at least two integrated computers are required to exchange the information. In this system, production can respond quickly with less error. Finally, the most important capacity of this system is cooperative automation [22].

The identification and analysis of the best practices applied by the company under study, regarding the new technologies that are being implemented for Industry 4.0, pointed out as a highlight the Online Predictive Maintenance that aims to obtain predictability of failure for each component monitored in machines and equipments.

Using vibration and temperature sensing for the monitoring of machines and equipments of interest, data is sent in real time through the collection and reading devices of sensors called gateways, to supervisory software and web platforms that are responsible for the consolidation and display of the datas in order to facilitate reading and interpretation through charts and reports.

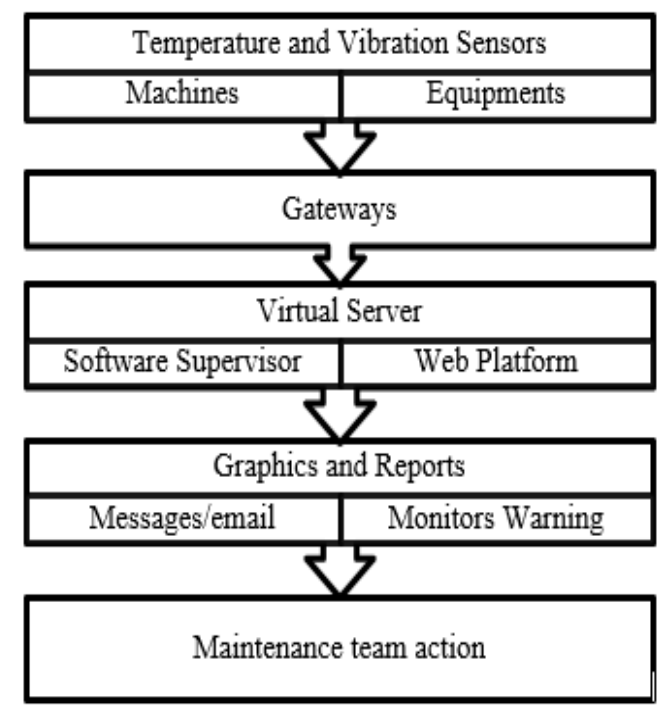

Fig. 1: Flow chart corresponding to the Online Predictive Maintenance process

Souce: Own elaboration (2018).

In order to monitor the faults, critical warnings are sent by email, messages to mobile devices, and through the graphics displayed on the monitors as well, increasing the efficiency of predictive maintenance and reducing corrective maintenance activities, as noted in the flowchart below. Figure 1 shows the flowchart corresponding to the Online Predictive Maintenance process.

With the specific monitoring of the machines and equipment in the company under study, it is possible to observe standards in its operation and through the connection with CPS, the immediate analysis of data allows the identification of possible future failures through small changes in its graphs of operation. In this way, operators and maintenance managers are able to visualize, by their devices and by means of the notices issued, the necessary information of the reports. At the same time, the system shows the defective part and fire the maintenance team, which at the next production stop moves with the component to be replaced at hand and performs the necessary operation, thus optimizing maintenance without stopping production unexpectedly because of a piece breaking.

This operating routine confirms how much mental processes will be required in the context of the Industry 4.0 scenario, since it was verified a high flow of information associated with rapid decision-making in the use of the new technologies was so that a growing industrial complexity in to a process of technological virtualization will require new skills of this professional.

This operating routine confirms how much mental processes will be required in the context of the Industry 4.0 scenario, since it was verified a high flow of information associated with rapid decision-making in the use of the new technologies, so that it will require new skills of the professionals.

The correct application of engineering knowledge's leads to the critical analysis of the required employee's qualifications inserted in the context of advanced manufacturing and industrial internet, specifically the socalled Engineer 4.0, allowing listing four essential requirements: (1) interdisciplinary training; (2) adaptability; (3) sense of urgency; and (4) good interpersonal relationships. In fact, the engineer will have to break and surpass the search only for technical solutions to a problem, necessitating the interaction with professionals of diverse areas, of creativity and of the adaptive capacity $[9,1]$.

In front of the case study, it was also observed the operator's difficulty to assimilate the new applied technologies, since previously it was used printed worksheets and general reports, so that, they did not deal with the volume of data now administered, raising the cognitive requirement of them, generating discomfort for the unknown and fear of possible layoffs for performance. For the improvement of cognitive ergonomics, we suggest 
the matrix training by area, divided in 4 steps, from $A$ to $\mathrm{D}$, in which the scope is adapted by operation, teaching them the operation of the general monitoring system until the operation that must be performed.

It was observed a significant improvement in operation and productivity after the completion of training. The load of cognitive requirements was maintained, but with the assimilation of the new technologies and the correct learning of the operation of them, it helped the operators in the execution of their activities.

\section{CONCLUSION}

The fourth industrial revolution brings with it a new paradigm, based on advanced manufacturing and industrial internet. Thus, it has been found that the requirement for mental and cognitive processes within the scope of industry 4.0 will certainly be distinct from that required in traditional industry due to the flow and speed of information transmission, the needing for accelerated decision-making and approaches based on intelligent systems, demanding from the professional many intellectual activities, so that enter the cognitive ergonomics study area. In addition, it is a consensus that there is no standardization of information on the subject matter, especially in the academic field, difficulty more in-depth investigations by scientific community.

The case study developed highlighted the Online Predictive Maintenance, which aims to obtain predictability of failure for each component monitored in machines and equipment. The operating routine linked to this new technology confirms how much the mental processes will be required in the scenario of Industry 4.0, since a high flow of information was verified, as sociated to the rapid decision making in the use of the new technologies.

In fact, specifically in the field of Engineering, much has been debated about the Engineer 4.0 formation, and in this study, it was found that the engineer will be connected to the solution of increasingly complex problems in a digital environment, requiring denser cognitive efforts and skills socio-emotional, such as communication, motivation, autonomy, perseverance, self-control, resilience, collaboration and creativity.

\section{REFERENCES}

[1] Shafiq L, Sanin C, Szczerbicki E, Toro C. (2015). "Virtual Engineering Object/Virtual Engineering Process: Aspecialized form of Cyber Physical System for Industrie 4.0." Procedia Computer Science, 60, pp 1146 - 1155.

[2] Toro C, Barandiaran I, Posada J. (2015). "A perspective on Knowledge Based and Intelligent systems implementation in Industrie 4.0." Procedia Computer Science, 60, pp. 362 - 370.

[3] Brettel M, Friederichsen N, Keller M, Rosenberg M. (2014). "How Virtualization, Decentralization and Network Building Change the Manufacturing Landscape: An Industry 4.0 Perspective." International Journal of Mechanical, Industrial Science and Engineering, 8, pp. 37-44.

[4] Kagermann H. (2014). "Chancen von Industrie 4.0 nutzen." In: Bauernhansl TM, Hompel T, VogelHeuser B, (eds). "Industrie 4.0 in Produktion, Automatisierung und Logistik. Anwendung." Technologien und Migration, pp. 603-614.

[5] Plattform Industire 4.0. (2013). Plattform Industrie 4.0.: Industrie 4.0 - Whitepaper FuEThemen, http://www.plattformi40.de/sites/default/files/White paper Forschung\%20Stand\%203.\%20April\%20201 4 0.pdf, acess: 02.20.2018.

[6] Astarloa A, Bidarte U, Jiménez J, Zuloaga A, Lázaro J. (2016). "Intelligent gateway for Industry 4.0 compliant production, IECON 2016." 42nd Annual Conference of the IEEE Industrial Electronics Society, Florence, pp. 4902-4907.

[7] Bauernhansl T. (2014) "Die vierte industrielle Revolution." Der Weg in ein wertschaffendes Produktionsparadigma, In: Bauernhansl T, Hompel T, Vogel-heuser B. (eds). "Industrie 4.0 in Produktion, Automatisierung und Logstik." Anwendung, Technologien und Migration, pp. 3-35.

[8] Lee, EA. (2008). "Cyber physical systems: design challenges." In 11th IEEE Symposium on Object and Component-Oriented Real-Time Distributed Computing (ISORC), pp. 363-369.

[9] Smartfactorykl. (2014). Keyfinder production line. http://smartfactory.dfki.uni-

$\mathrm{kl}$.de/en/content/demo/technological-demo/plantindustry4. acess: 02.20.2018.

[10] Herman M, Pentek T, Otto B. (2015). "Design principles for Industrie 4.0 scenarios. Technical University of Dortmund." Faculty of Engimeering, Audi Endowment Chair Supply Net Order Management. $\quad$ http://www.snom.mb.tudortmund.de/cms/de/forschung/Arbeitsberichte/Desi gn-Principles-for-Industrie-4 0-Scenarios.pdf, acess: 03.04.2018.

[11] IEA. International Ergonomics Association. (2017). The Discipline of Ergonomics, www.iea.cc/ergonomics. acess: 03.03.2018.

[12] Moraes Ade, Monfalvão C. (1998). "Ergonomia: Conceitos e aplicações." Série Design, Rio de Janeiro, Brazil.

[13] IIDA I. (2003). "Ergonomia: projeto e produção." 9th ed, Edgard Blücher. São Paulo, Brazil. 
[14] Falzon P. (2007). "Ergonomia.” Edgard Blücher. São Paulo, Brazil.

[15] Creswell, J. W. (1998). "Qualitative inquiry and research design: Choosing among five traditions." Thousand Oaks, CA, US.

[16] Stake R. (1982). "Naturalistic generalization." Review Journal of Philosophy and Social Science, vol 7, pp 1-12.

[17] Lucke D, Constantinescu C, Westkamper E. (2008). "A Step towards the Next Generation of Manufacturing, in: Manufacturing Systems and Technologies for the New Frontier." Springer London, pp. 115-118.

[18] Kagermann H, Helber J, Hellinger A, Wahlster W. (2013). "Recommendations for Implementing the Strategic Initiative INDUSTRIE 4.0: Securing the Future of German Manufacturing Industry." Final Report of the Industrie 4.0 Working Group. Forschungsunion.

[19] Abramovici M. (2013). Smart Product Engineering.

[20] [19] Schlechtendahl J, Keinert M, Kretschmer F, Lechler A, Verl A. (2015). "Making existing production systems Industry 4.0." Prod. Eng. Res. Devel, 9, pp. 143-148.

[21] Kowal J. (2014). "Industry 4.0 and industrial Internet of Things are automation investment opportunities." Control Engineering, 6, pp. 46-47.

[22] Groover M. (2007). "Single-station manufacturing cells, Automation, production systems, and computer-integrated manufacturing." Prentice Hall Press, pp. 383-393.

[23] Alavudeen A, Venkateshwaran N. (2008). Computer integrated manufacturing, PHI Learning Pvt. Ltd. 